\title{
Pregnancy Outcome
}

National Cancer Institute

\section{Source}

National Cancer Institute. Pregnancy Outcome. NCI Thesaurus. Code C90491.

Findings observed at the end of a pregnancy. 